\title{
Water Mass Characteristics and Stratification at the Shallow Sunda Shelf of Southern South China Sea
}

\author{
Nur Hidayah Roseli' ${ }^{1}$ Mohd Fadzil Akhir ${ }^{1 *}$, Mohd Lokman Husain ${ }^{1}$, \\ Fredolin Tangang' ${ }^{2}$, Azizi Ali ${ }^{1}$ \\ ${ }^{1}$ Institute of Oceanography and Environment, Universiti Malaysia Terengganu, Kuala Terengganu, Malaysia \\ ${ }^{2}$ Research Centre for Tropical Climate Change System, National University of Malaysia, Bangi, Malaysia \\ Email: ${ }^{*}$ mfadzil@umt.edu.my
}

Received 24 August 2015; accepted 24 October 2015; published 27 October 2015

Copyright (C) 2015 by authors and Scientific Research Publishing Inc.

This work is licensed under the Creative Commons Attribution International License (CC BY).

http://creativecommons.org/licenses/by/4.0/

(c) (i) Open Access

\begin{abstract}
CTD data obtained from two oceanographic cruises during June and October 2012 were used to define the water mass characteristics and degree of stratification at the shallow Sunda shelf located at the southern South China Sea. The water masses during both cruises showed characteristics similar (southwest monsoon) to those observed in the adjacent regions. A clustering method was used in which three water masses were classified from the composite dataset. There are WM1 $\left(T 29^{\circ} \mathrm{C}-31^{\circ} \mathrm{C}, S 32-33.5 \mathrm{psu}, \& \sigma_{\mathrm{T}}, \sim 19.5-20.7 \mathrm{~kg} / \mathrm{m}^{3}\right), \mathrm{WM} 2\left(T 25^{\circ} \mathrm{C}-29^{\circ} \mathrm{C}, S 32.8-33.8 \mathrm{psu}, \& \sigma_{\mathrm{T}}\right.$, $\left.\sim 22.3-23 \mathrm{~kg} / \mathrm{m}^{3}\right)$ and $W M 3\left(T 23^{\circ} \mathrm{C}-25^{\circ} \mathrm{C}, S 33.5-34.0, \& \sigma_{\mathrm{T}} \sim 22.3-23.3 \mathrm{~kg} / \mathrm{m}^{3}\right)$. Even though the water masses found were characterized under southwest monsoon characteristics, the degrees of stratification obtained varied between these cruises. The stability of the stratification also plays roles in the distribution of the water masses in the water column. WM2 was found in thermocline layer and most dominant in June compared to in October. In June, WM3 was found under the thermocline layer and absent in October. The stable thermocline caused the denser WM3 cannot mixed with WM2. Higher temperatures and weaker winds during June may have caused the strong stratification, while decreasing temperature and stronger winds of an upcoming northeast monsoon enhanced the vertical mixing during October.
\end{abstract}

\section{Keywords}

Water Masses, Stratification, Brunt-Vaisala Frequency, Sunda, Shelf, South China Sea

\footnotetext{
${ }^{*}$ Corresponding author.
}

How to cite this paper: Roseli, N.H., Akhir, M.F., Husain, M.L., Tangang, F. and Ali, A. (2015) Water Mass Characteristics and Stratification at the Shallow Sunda Shelf of Southern South China Sea. Open Journal of Marine Science, 5, 455-467. 


\section{Introduction}

Sunda shelf located at the southern region of the South China Sea is a shallow continental shelf with a depth averaging less than $100 \mathrm{~m}$. It becomes a connection between Southeast Asia, Malaysia, Sumatra, Java and Borneo. Previous studies suggested that the entire system of South China Sea including Sunda shelf is under the influence of monsoon systems, a northeast monsoon (November-February) and a southwest monsoon (June-September) (e.g., [1]-[8]). Between these two monsoons, two transitional periods are clearly distinguishable. They usually occur in April and October and tend to last for about four to seven weeks [1] [9] [10].

The study on water masses distribution at this continental shelf; especially in Malaysian water was almost none. There was a study performed by [11] at the coastal off east coast peninsular Malaysia and found the water mass during southwest monsoons to range from $27.5^{\circ} \mathrm{C}-30.5^{\circ} \mathrm{C}$ (temperature) and $32-33.5 \mathrm{ppt}$ (salinity). During the northeast monsoons, the water mass ranged from $27.5^{\circ} \mathrm{C}-29.5^{\circ} \mathrm{C}$ (temperature) and $30-31.5 \mathrm{ppt}$ (salinity). This study, however, does not define specific water masses as done by [8] [12] at Vietnamese water, the nearest location to Malaysian water. By using CTD data collected at 56 stations off Vietnamese water from April 30 to May 29, 1999, [12] defined seven water masses as presented in Table 1. The CTD used was casted at maximum depth of $\sim 1500 \mathrm{~m}$. After several years, [8] redefined the water masses listed by [12] with new water mass definition. The redefinition was made because there were some problems in separating the observations into different water masses made by [12]. There were several observations that do not fit into the given water mass definition. [8] then used a comprehensive temperature and salinity datasets from 331 CTD casts at the Vietnamese water to specify the new "end member" for mixing of water masses. The new water masses are listed in Table 2. Not too far from the study area, almost similar water masses as found by [8] [12] are also found by [13]. The datasets were collected at the south-western part of the Taiwan Strait in four cruises in the summer

Table 1. Water mass characteristics defined by [12]: deep water (DW), permanent thermocline water (PTW), maximum salinity water (MSW), seasonal thermocline water (STW), open sea water (OSW), northern continental shelf water (NCSW), and southern continental shelf water (SCSW).

\begin{tabular}{ccc}
\hline Water Mass & Temperature $\left({ }^{\circ} \mathbf{C}\right)$ & Salinity (psu) \\
\hline DW & $2.5-5$ & $34-35$ \\
PTW & $10-15$ & $34-35$ \\
MSW & $15-20$ & $>34.5$ \\
STW & $20-27$ & $34-35$ \\
OSW & $25-29$ & $33-34$ \\
NCSW & $23-27$ & $31-33$ \\
SCSW & $29-31$ & $27-33$ \\
\hline
\end{tabular}

Table 2. Water masses characteristics defined by [8]: deep water (DW), permanent thermocline water (PTW), maximum salinity water (MSW), open sea water (OSW), Mekong/gulf of Thailand water (MKGTW), water mass 1 (WM1): mixed water between MSW and PTW, WM2: mixed water between MSW and OSW, WM3: mixed water between OSW and MKGTW, and WM4: mixed water between OSW, MKGTW and MSW. Noted that some of the water masses define by [8] can also be found in [12].

\begin{tabular}{ccc}
\hline Water Mass & Temperature $\left({ }^{\circ} \mathbf{C}\right)$ & Salinity (psu) \\
DW & $<2.5$ & $>34.6$ \\
PTW & $7-9$ & $34.4-34.5$ \\
MSW & $17-19$ & $>34.3$ \\
OSW & $26-31$ & $33.7-34.1$ \\
MKGTW & $27-31$ & $<32.9$ \\
WM1 & $9-17$ & $34-35$ \\
WM2 & $19-28$ & $34.1-34.6$ \\
WM3 & $26-31$ & $32.9-33.7$ \\
WM4 & $22-26$ & $33.3-34.1$ \\
\hline
\end{tabular}


Table 3. The core values of summertime mean of temperature and salinity of water masses characteristics defined by [2]: coastal diluted water (CDW), upper warm water (UWW), mixed water (MW), upwelled water (UW) and subsurface water (SW).

\begin{tabular}{ccc}
\hline Water Mass & Temperature $\left({ }^{\circ} \mathbf{C}\right)$ & Salinity (psu) \\
CDW & 28.58 & 30.06 \\
UWW & 29.30 & 33.01 \\
MW & 25.49 & 33.77 \\
UW & 21.80 & 34.36 \\
SW & 15.75 & 34.52 \\
\hline
\end{tabular}

(2004-2007). [13] calculated the core values of temperature and salinity for each water masses and it is presented in Table 3.

When discussing stratification at the east coast of Peninsular Malaysia water, past researchers found greater stratification of temperature and salinity in the southwest monsoon than in the northeast monsoon [14]-[16]. The thermocline was more prominent in the southwest monsoon period and absent during the northeast monsoon. The halocline is not apparent in both seasons, except in surface salinity, which showed horizontal stratification in the nearshore to offshore direction during the southwest monsoon [14]. [12] found the shallower homogenous layer of temperature and salinity during the southwest monsoon while during the northeast monsoon, the homogeneous layer was deeper, started at depths of 70 to $90 \mathrm{~m}$. The stratification was most developed in April-May because of strong sea surface heating and weak sea surface winds [16]. Well-mixed conditions during the northeast monsoon at South China Sea were because of stronger winds that enhance mixing [11].

Both, defining water mass characteristics and calculating stratification frequency which previously has never been conducted objectively will be done in this study to increase the number of publications in this region. The informative findings found in this study would bring new contribution to knowledge which beneficial to other studies. Temperature and salinity data from CTD casts in two different seasons (southwest monsoon and transitional period) were used to define the water mass characteristics at the shallow Sunda shelf, particularly in the east coast Peninsular Malaysia. Besides, the stratification frequency also will be calculated to determine whether there are any variations in the degree of stratification taken in two different periods and also its role in the distribution of water masses.

\section{Data and Methods}

\subsection{Field Data Collections}

Two oceanographic cruises aboard KL Cermin (a vessel from Malaysian Fisheries Department) spanning across the Sunda shelf of east coast Peninsular Malaysia EEZ (Exclusive Economic Zone) were conducted from 27 June-1 July 2012 (KLCO2/12) and 14-18 October 2012 (KLC03/12) (hereafter referred to as June and October, accordingly). Each cruise consisted of four transects across the shelf and along the east coast Peninsular Malaysia (Figure 1). Distances between stations are 40 - $60 \mathrm{~km}$ for June cruise and 20 - $30 \mathrm{~km}$ for October cruise. The farthest sampling stations are located $\sim 287 \mathrm{~km}$ from the coast, while the nearest sampling stations are $30 \mathrm{~km}$ from the coast. There were 56 total sampling stations, which are illustrated in Figure 1.

The in-situ temperature and salinity were measured with a SBE Plus19v2 CTD (Conductivity-TemperatureDepth Pressure) manufactured by the Sea-Bird Company. SBE Plus19v2 CTD casts at a $4 \mathrm{~Hz}$ sampling rate were self-recorded into the installed program in the connected device. The data were then bin averaged into 1-m depths using SBE Data Processing.

Hourly of meteorological wind data recorded at the Kuala Terengganu Airport was used in this study (refer to map in Figure 1 for the location of Kuala Terengganu). Recorded wind data was obtained from the Malaysian Meteorological Department (MMD). The sensor was deployed $6 \mathrm{~m}$ above the sea surface. Wind stress was then calculated based on the solutions described by [17].

\subsection{Cluster Analysis}

Cluster analysis was applied to classify the water mass distributions obtained in the cruises. In this study, the 

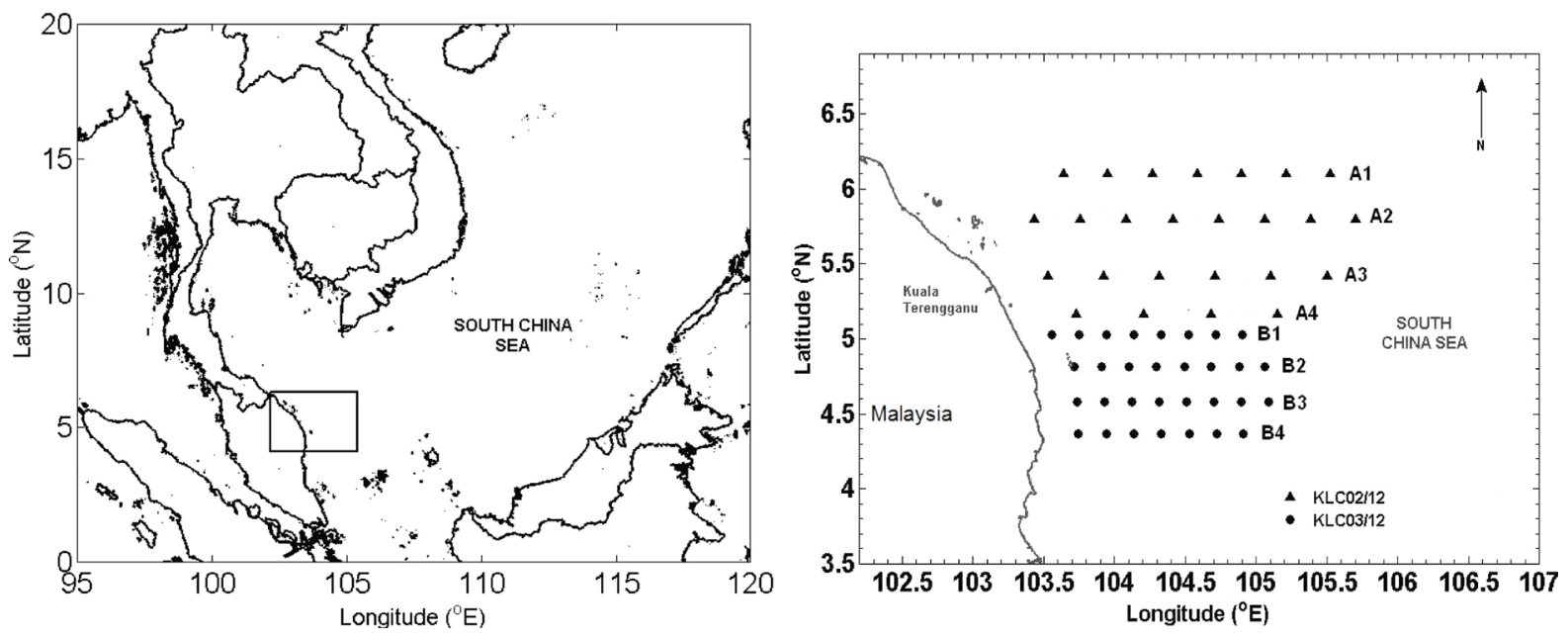

Figure 1. Sampling stations for KLC02/12 (June) and KLC03/13 (October) cruises. Line A1, A2, A3 and A4 are four transects in cruise KLC02/12 (June). Line B1, B2. B3 and B4 are four transects in cruise KLC03/12 (October).

clustering algorithm that will be used is called the $k$-mean. $K$-mean is a well-known partitioning method which aims to partition $n$ observations into $k$ clusters in which each observation belongs to the cluster with the nearest mean. Euclidean distance function is used in order to combine cluster points consist of temperature and salinity. For validation of clustering results in cluster analysis, it was important to use some objective measures to evaluate the clustering quality. The silhouette method that was first described by [18] was used as the tool to validate the clustering results. The technique provided a succinct graphical representation of how well each object lies within its cluster.

Assumed the data have been clustered via any technique, such as $k$-means, into $k$ clusters (as applied in this study). For each datum $i$, let $a(i)$ be the average dissimilarity of $i$ with all other data within the same cluster. Silhouette width is a composite index reflecting the compactness and separation of the clusters, and can be applied to different distance metrics. Distance measure is used to interpret $a(i)$ as how well $i$ is assigned to its cluster (the smaller the value, the better the assignment). The average dissimilarity of point $i$ to a cluster $c$ is the average of the distance from $i$ to points in $c$.

Let $b(i)$ be the lowest average dissimilarity of $i$ to any other cluster which $i$ is not a member. The cluster with this lowest average dissimilarity is said to be the "neighbouring cluster" of $i$ because it is the next best fit cluster for point $i$. It is define as:

$$
s(i)=\frac{b(i)-a(i)}{\max \{a(i), b(i)\}}
$$

Which can be written as

$$
s(i)= \begin{cases}1-a(i) / b(i), & \text { if } a(i)<b(i) \\ 0, & \text { if } a(i)=b(i) \\ b(i) / a(i)-1, & \text { if } a(i)>b(i)\end{cases}
$$

From the above definition it is clear that,

$$
-1 \leq s(i) \leq 1
$$

For $s(i)$ to be close to 1 we require $a(i) \ll b(i)$. As $a(i)$ is a measure of how dissimilar $i$ to its own cluster, a small value means it is well matched. Furthermore, a large $b(i)$ implies that $i$ is badly matched to its neighbouring cluster. Thus $s(i)$ is close to one means that the datum is appropriately clustered. If $s(i)$ is close to negative one, then by the same logic we see that $i$ would be more appropriate if it was clustered in its neighbouring cluster. An $s(i)$ near zero means that the datum is on the border of two natural clusters. The average $s(i)$ over all data of a cluster is a measure of how tightly grouped all the data in the cluster are. Therefore, the average $s(i)$ over all 
data of the entire dataset is a measure of how appropriately the data has been clustered. If there are too many or too few clusters, as may occur when a poor choice of $k$ is used in the $k$-means algorithm, some of the clusters will typically display much narrower silhouettes than the rest. Thus silhouette plots and averages may be used to determine the natural number of clusters within a dataset. A larger averaged silhouette width indicates a better overall quality of the clustering result [19]. However, the samples with a greater number of incorrect clusters cannot be considered as the best result [20]. The calculation of the k-mean and silhouette test in this study was performed by using a programming tool in Matlab.

\subsection{Stratification Frequency}

In this study, the square of the buoyancy frequency (often called Brunt-Vaisala frequency), $\mathrm{N}^{2}$, was used to represent the stratification. $\mathrm{N}^{2}$ was calculated under the GSW computer toolbox of TEOS-10 (The International Thermodynamic Equation of Seawater-2010) in Matlab. The functions used under TEOS-10 calculate $\mathrm{N}^{2}$ according to the absolute salinity and conservative temperature as their input salinity and temperature, and the functions also used the computationally efficient 25-term expression for density from [21]. Brunt-Vaisala Frequency is defined as

$$
N^{2}=\frac{g}{\rho} \frac{\Delta \rho^{\odot}}{\Delta z}=\frac{g^{2} \Delta \rho^{\odot}}{\Delta P}
$$

where, $N=$ Brunt-Vaisala frequency, $g=$ gravitational force, $\rho=$ potential densities, $\Delta \rho^{\odot}=$ difference between potential densities of two water parcels with the reference pressure being average of the two original pressure of the seawater parcels. The last part of equation $\Delta P$ is derived from hydrostatic relation of $P_{z}=-g \rho$. In term of static stability in the ocean, stratification is stable and does not overturn locally if $N^{2}>0$.

\section{Results and Discussion}

\subsection{Water Masses Analysis}

The composited data of temperature and salinity obtained from both cruises are presented in the typical entropy diagram or temperature-salinity curve (Figure 2) to identify the water masses that existed. The T-S curve appeared to have similar characteristics to the southwest monsoon water mass, as observed by [11]. It showed that for months of June (southwest monsoon) and October (transitional period), the temperature and salinity shared similar southwest monsoon properties.

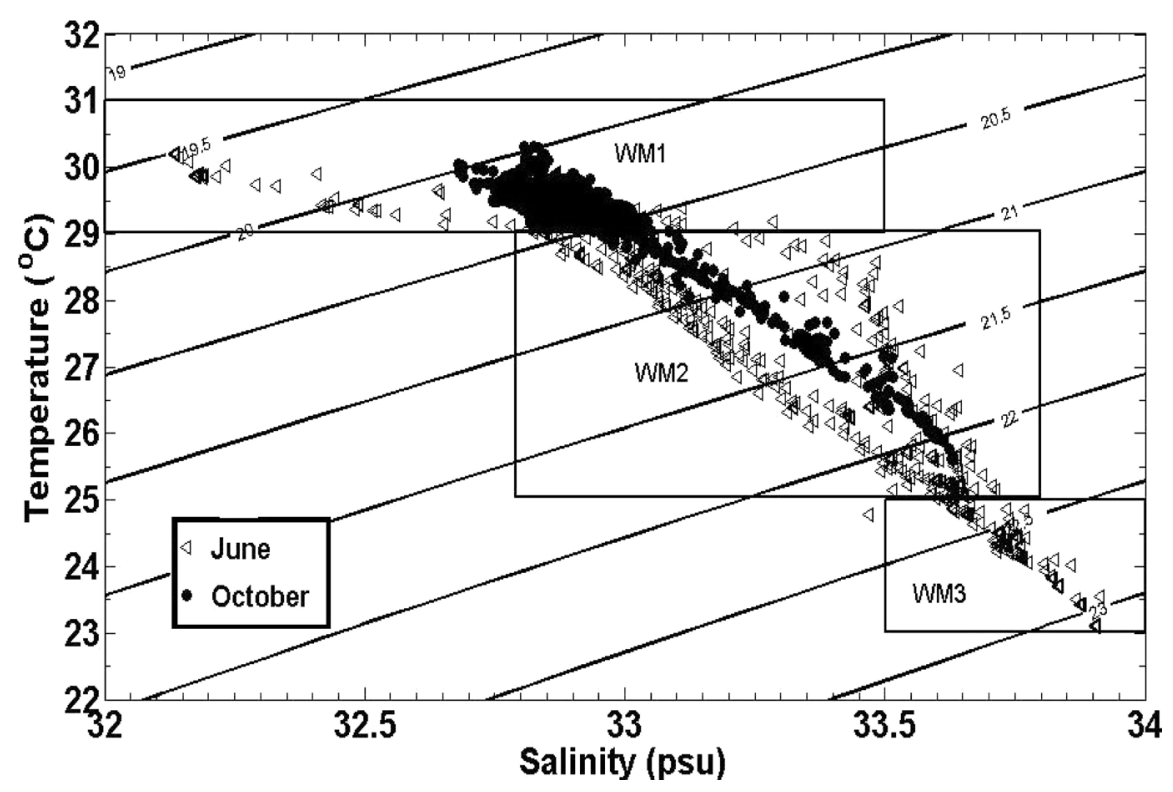

Figure 2. Typical entropy diagram (T-S diagram) of temperature and salinity for June and October cruises. Triangle symbols are June data, while dot points are October data. 
Cluster analysis method was used to classify the water masses from the composited temperature and salinity data. A silhouette value method was then applied to statistically test the clustering results (Figure 3). In this test, the largest index, or the silhouette value nearest to one, determined the highest quality cluster values. However, the samples that were poorly clustered (negative values) cannot be considered to display the best results [20]. According to Figure 3, the largest index of silhouette values was cluster number two (Figure 3(a)), but the poorly clustered samples showed greater values than cluster number three (Figure 3(b)). Thus, cluster number three was selected because it had fewer poorly clustered samples and had the largest index. According to the cluster analysis, these three water masses now have been distinguished and presented in Table 4.

Prevalent dominance of warmer and less saline water named as WM1 was characterized by temperatures between $29^{\circ} \mathrm{C}-31^{\circ} \mathrm{C}$ and salinity between $32-33.5 \mathrm{psu}$, and density, $\sigma_{T}$, can be distinguished as being between $\sim 19.5-\sim 20.7 \mathrm{~kg} / \mathrm{m}^{3}$. The accumulated points in between the isopycnal range shown in the T-S curve indicated that it is part of the mixed water feature at the surface in the nearshore area of east coast Peninsular Malaysia (Figure 2). This also can be seen at the surface cross-section of both cruises (Figure 4 \& Figure 5). In both cruises, WM1 spread consistently from southern to northern area of east coast Peninsular Malaysia water (Figure 4 \& Figure 5). However, this water mass was more dominant in October compared to June. Strong wind recorded by MMD in October presumably enhance the mixing at the surface caused this water mass to be more dominant in October (Table 5). WM1 with almost similar range of temperature and salinity, was also found by [8], [12] in a study of water masses at the Vietnamese coasts. The temperature and salinity values found by [12] were $27.0^{\circ} \mathrm{C}-31.0^{\circ} \mathrm{C}$ and 27 - 33 psu, respectively, which were similar to our findings, but with a lower salinity minimum. The authors labelled this water mass as Southern Continental Shelf Water (SCSW).

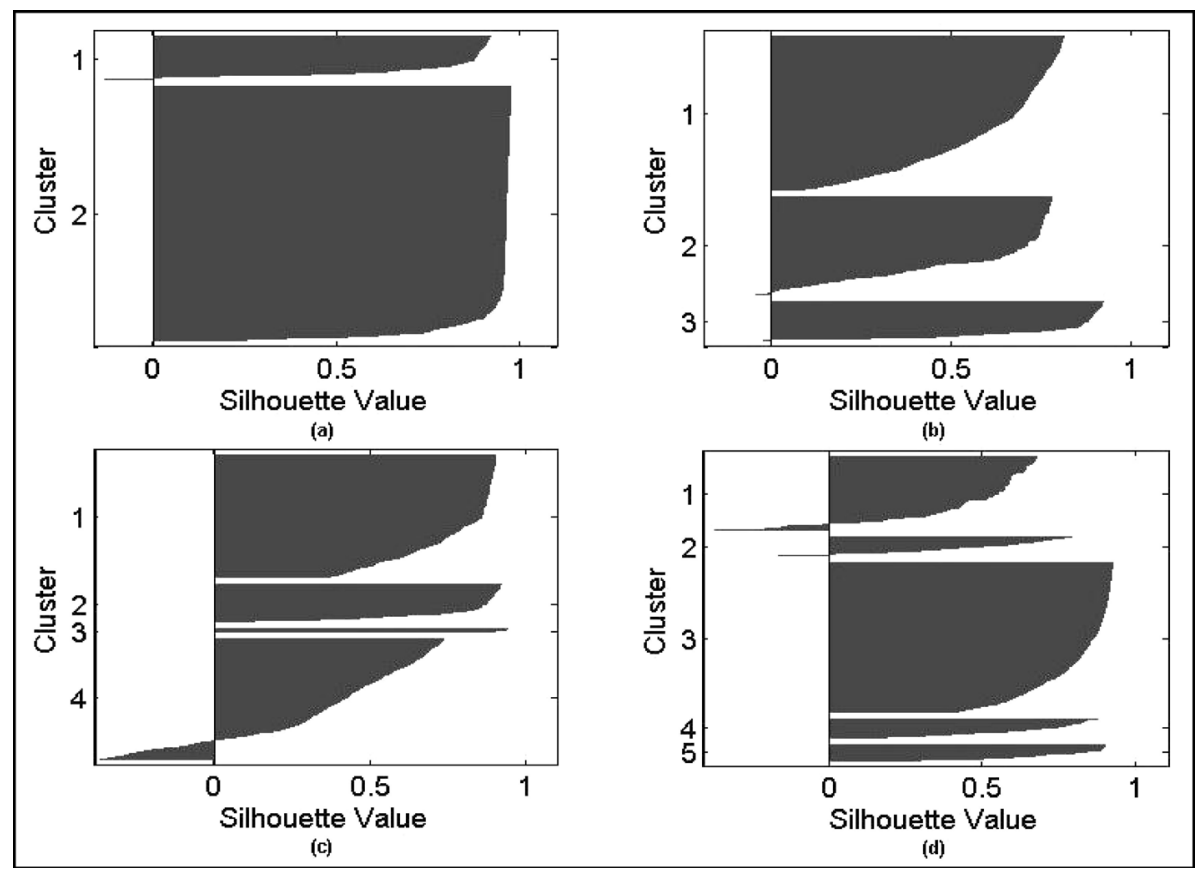

Figure 3. Silhouette test for the values of (a) 2, (b) 3, (c) 4 and (d) 5.

Table 4. Comparison of water masses found in this study with the other studies. please refer Table 1 , Table 2 and Table 3 for more details regarding water masses characteristic defined by past researchers.

\begin{tabular}{|c|c|c|c|}
\hline Present Study & Rojana-anawat et al. (2000) & Dippner et al. (2011) & Hu et al. (2011) \\
\hline WM1: $T 29^{\circ} \mathrm{C}-31^{\circ} \mathrm{C}$ & SCSW: $T 29^{\circ} \mathrm{C}-31^{\circ} \mathrm{C}$ & \multirow{3}{*}{$\begin{array}{c}\text { WM3: } T 26^{\circ} \mathrm{C}-31^{\circ} \mathrm{C} \\
\text { S } 32.9-33.7 \mathrm{psu}\end{array}$} & \multirow{3}{*}{$\begin{array}{c}\text { UWW: } T 29.30^{\circ} \mathrm{C} \text { (core) } \\
\text { S } 33.01 \text { psu (core) }\end{array}$} \\
\hline S $32-33.5$ psu & S $27-33$ psu & & \\
\hline $\begin{array}{c}\mathrm{WM} 2: \mathrm{T} 25^{\circ} \mathrm{C}-29^{\circ} \mathrm{C} \\
S 32.8-33.8 \mathrm{psu}\end{array}$ & $\begin{array}{c}\text { OSW: } T 25^{\circ} \mathrm{C}-29^{\circ} \mathrm{C} \\
\text { S } 33-34 \mathrm{psu}\end{array}$ & & \\
\hline $\begin{array}{c}\text { WM3: } T 23^{\circ} \mathrm{C}-25^{\circ} \mathrm{C} \\
\text { S } 33.5-34 \mathrm{psu}\end{array}$ & & $\begin{array}{c}\text { WM4: } T 22^{\circ} \mathrm{C}-26^{\circ} \mathrm{C} \\
\text { S } 33.3-34.1 \mathrm{psu}\end{array}$ & $\begin{array}{c}\text { MW: } T 25.49^{\circ} \mathrm{C} \text { (core) } \\
\text { S } 33.77 \text { psu (core) }\end{array}$ \\
\hline
\end{tabular}



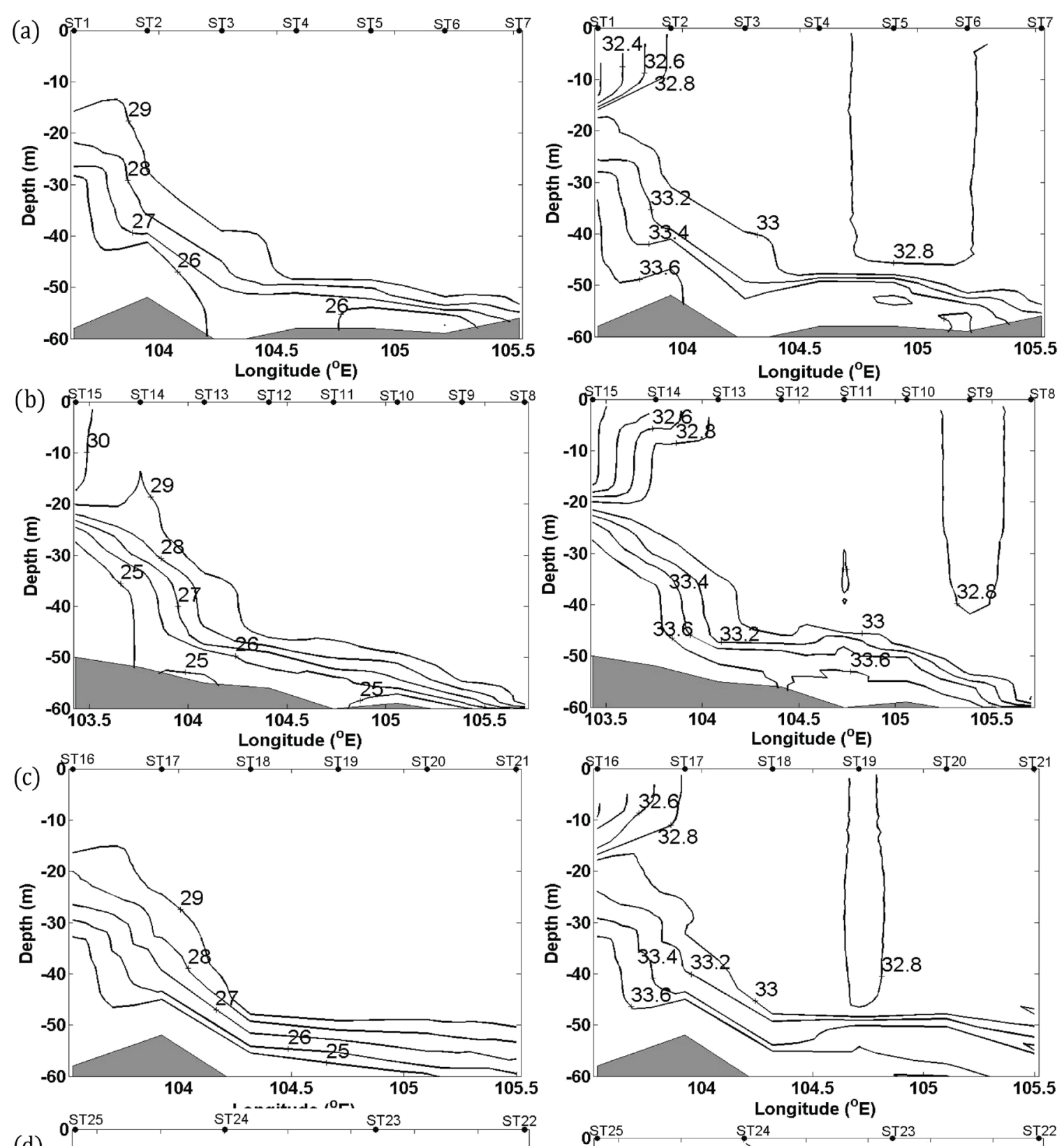

(d)
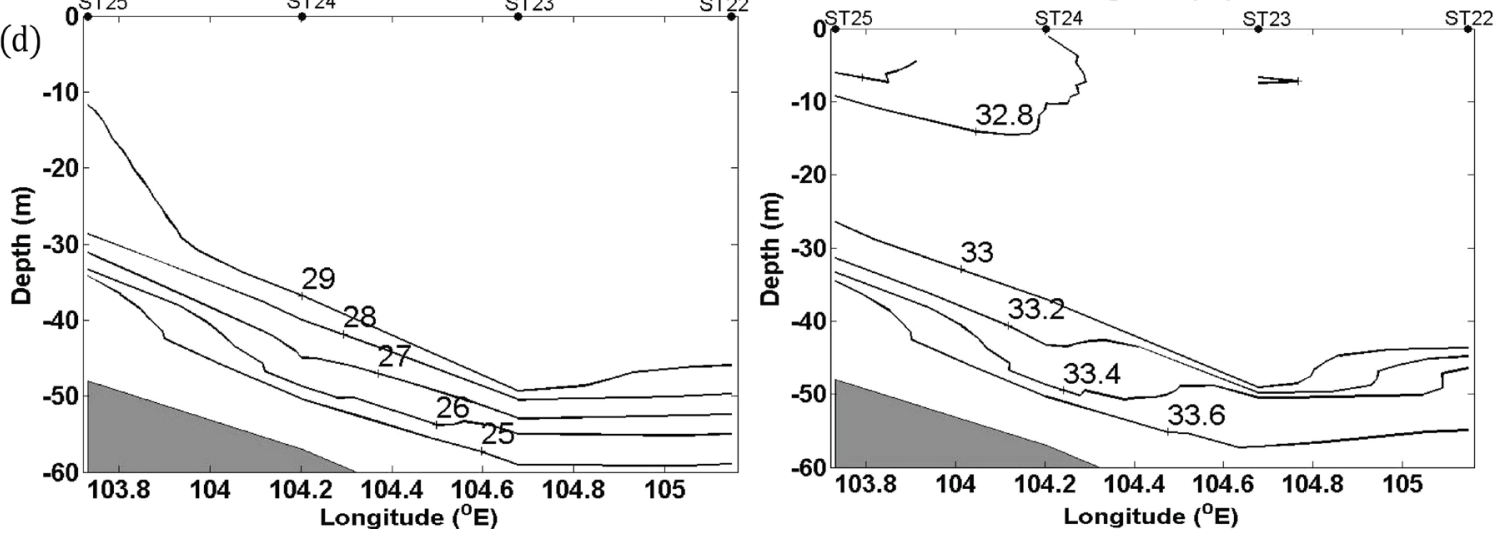

Figure 4. Cross-section of temperature (left) and salinity (right) in accordance of all of the transects (a) A1, (b) A2, (c) A3 and (d) A4 for June cruise. Temperature unit is in ${ }^{\circ} \mathrm{C}$ and salinity is in psu. 

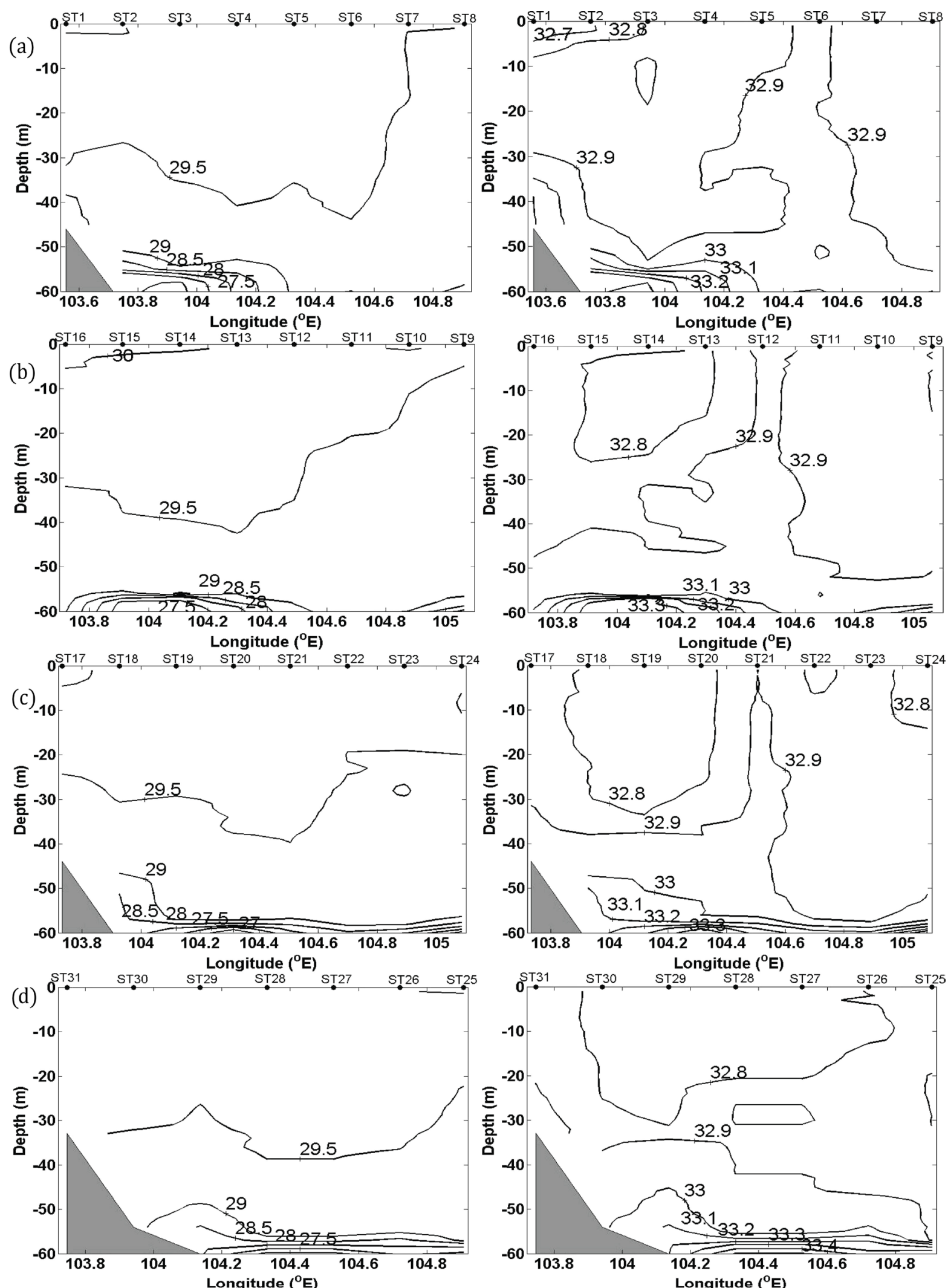

Figure 5. Cross-section of temperature (left) and salinity (right) in accordance of all of the transects (a) A1, (b) A2, (c) A3 and (d) A4 for October cruise. Temperature unit is in ${ }^{\circ} \mathrm{C}$ and salinity is in psu. 
Table 5. Wind and tides information obtained from Malaysian meteorological department for wind and deployed acoustic wave and current for tidal data.

\begin{tabular}{cccccc}
\multirow{2}{*}{ Cruises } & \multicolumn{2}{c}{ Wind Stress (N/m2) } & \multicolumn{2}{c}{ Wind Speed (m/s) } & \multirow{2}{*}{ Mean Wind Direction } \\
\cline { 2 - 5 } & Min & Max & Min & Max & \\
June & 0.0007 & 0.0121 & 0 & 3.3 & Northward \& Westward \\
October & 0.0023 & 0.0238 & 0.5 & 4.1 & Northward \& Southward \\
\hline
\end{tabular}

The water mass define by [8] that almost similar to our findings were ranged from $26^{\circ} \mathrm{C}-31^{\circ} \mathrm{C}$ and $32.9-33.7$ psu. This is the mixed water between MSW and OSW (Table 2). In the study by [13] in the southwestern Taiwan Strait (Cruise June-July 2006), almost similar water mass as WM1 with a core temperature and a salinity of $29.14^{\circ} \mathrm{C}$ and $32.34 \mathrm{psu}$, respectively was found. This water mass was labelled as Upper Warm Water (UWW).

Another water mass found in this study was labelled as WM2 which lied between density, $\sigma_{T}=\sim 22.3-\sim 23$ $\mathrm{kg} / \mathrm{m}^{3}$. WM2 in this study was stratified water mass ranged between $25^{\circ} \mathrm{C}-29^{\circ} \mathrm{C}$ and $32.8^{\circ} \mathrm{C}-33.8 \mathrm{psu}$, as shown by the straight line across the isopycnal lines in the T-S curve (Figure 2). In the cross sectional plots (Figure 4 \& Figure 5), this denser water mass lies below the WM1. The formation of vertical stratification in the water column was a consequence of water masses with different densities, which were formed depending on the temperature and salinity. It caused the cold and saline water of WM2, which was more dense, to sink below the warm and less saline water of WM1. The vertical location of this water mass varied in depth depending on the conditions of sea surface heating and winds during each season. In June, this water mass was found in the shallower water column, while in mid-October it was found in the deeper water column. It was also more dominant in June compared to October. WM2 was similar to the Open Sea Water (OSW) found by [12] and characterized by temperature and salinity of $25^{\circ} \mathrm{C}-29^{\circ} \mathrm{C}$ and $33-34 \mathrm{psu}$. This water mass, however, was defined by [8], [13] have similar water mass range as WM1.

The water mass with the highest density of $\sigma_{T}=22.3-23.3 \mathrm{~kg} / \mathrm{m}^{3}$, WM3 is a water mass characterized by temperature and salinity of $23^{\circ} \mathrm{C}-25^{\circ} \mathrm{C}$ and $33.5-34.0 \mathrm{psu}$, respectively. This water mass was found at the deepest part of water column in June cruise and was absent in October. There was no similar water mass characteristics as WM3 was found by [12]. However, [8] had defined almost similar water mass as WM3 ranged from $22^{\circ} \mathrm{C}-26^{\circ} \mathrm{C}$ and $33.3-34.1$ psu. The authors mentioned that this water mass was a mixed water between OSW, MKGTW and MSW (Table 2). [13] also had defined water masses that shared almost similar characteristics as WM3 with core temperature and salinity of $25.49^{\circ} \mathrm{C}$ and $33.77 \mathrm{psu}$. Almost similar values of temperature and salinity to this water masses were also found at the bottom shelf ( $75 \mathrm{~m})$ of cross-section plots of temperature and salinity plotted by [22] using the data obtained from [23] in a study of the northern Taiwan Straits. However, this observation need to be confirmed whether the water mass shared similar characteristics since no definition of water mass was made by [22].

It is difficult to give water mass definition at the shallow water because neither temperature nor salinity is an absolute conservative property due to heat fluxes at the air-sea interface and due to precipitation and evaporation [8]. When compared our own findings with the others, the water masses in shallow east coast Peninsular Malaysia located at the southern South China Sea shared almost similar characteristics with some modification as other places. Whether the water mass transportation is from the southern South China Sea to the northern or vice versa need to be discussed more. [8] had discussed in detail how the water masses from North Pacific enter the South China Sea and became part of Vietnamese upwelling water. The variability in monsoon intensity due to ENSO modulation caused the water masses distribution varied every year of the sampling. Based on Oceanic Nino Index (ONI), in 2012 (sampling time), ENSO event was absent and the upwelling is normal due to normal southwest monsoon condition. As WM1 can be found in most of past studies, it showed this warmer, less dense water is the common water mass dominate the surface of northwestern to southwestern of South China Sea during normal southwest monsoon condition. WM2, stratified water mass that most dominant in June compared to in October and how the location varied with depth showed the modification of this water mass according to season. The normal season of southwest monsoon with weaker winds and greater temperatures in June enhanced the stratification at the study area caused WM2 to appear at the shallower depth. Stronger winds in mid-October deepening the mixed layer (Table 5) caused this WM2 appear at deeper depth.WM2 was not defined by [8] and [13] but was mentioned to characterize similar as WM1. As most of the water masses found in the Vietnamese water are part of upwelling water, it is presumably the water mass such as WM3 that only observed in June was 
flow to our study area according to upwelling system.

\subsection{Degree of Stratification}

Temperature and salinity in June and October, which consisted of 4 transects each, are demonstrated in Figure 4 and Figure 5, respectively. The left sides of the figures are the stations nearest to coastal area and to the right of the figures is the offshore area. Transect A1 is the northernmost part of east coast Peninsular Malaysia, while B4 is the southernmost part of east coast Peninsular Malaysia (Figure 1). Temperature and salinity recorded in June were $24.8^{\circ} \mathrm{C}-31^{\circ} \mathrm{C}$ and $31.98-33.75$ psu respectively while the in-situ temperature and salinity recorded in October ranged from $23.1^{\circ} \mathrm{C}-3.97^{\circ} \mathrm{C}$ and $32.68-33.63 \mathrm{psu}$.

The temperature cross section in Transect A1 showed the thermocline nearshore was much higher $(\sim 15 \mathrm{~m})$ when compared to offshore, which recorded a deeper thermocline of approximately $50 \mathrm{~m}$. This pattern of thermocline between nearshore and offshore is almost consistent in across the shelf. The thermocline showed a lifting feature consistently along $104.2^{\circ} \mathrm{E}$. Such feature is always associated with the presence of upwelling. In terms of salinity, the halocline occurred in similar depths as the thermocline, except at the surface of the nearshore area, where there was the presence of a strong stratification-like feature. This feature consisted of low salinity waters, which predictably came from low salinity nearshore water. Throughout all transects, this low salinity water spread from nearshore until $\sim 104^{\circ} \mathrm{E}$.

The temperature cross section in October showed almost homogenous temperatures $\left(29.5^{\circ} \mathrm{C}\right)$ from the surface to approximately $30-40 \mathrm{~m}$ depth. Notably, layers of the thermocline between $27.5^{\circ} \mathrm{C}-29^{\circ} \mathrm{C}$ lie very close to the bottom. In terms of salinity, the halocline occurred at similar depths to the thermocline. The existence of higher salinity at $104.5^{\circ} \mathrm{E}$, extending from the surface to deeper in the water column, was found across the shelf, except for transect B4. Unlike in June, the thermocline and halocline observed in October were deeper and occurred around a depth of $55 \mathrm{~m}$. Almost all cross sections were well mixed from the surface to a depth of $50 \mathrm{~m}$. Compared to the earlier cruise, there were slight humps in every cross-section at a similar location to thermocline lifting. This can be seen for both temperature and salinity (Figure 5).

The results discussed earlier (Figure 4 and Figure 5) showed that in each cruise, water properties from the northern to southern part of east coast Peninsular Malaysia were mostly consistent. Both cruises also shared similar southwest monsoon characteristics. However, the stratified layer varied between both cruises. The BruntVaisala frequency $\left(\mathrm{N}^{2}\right)$, often called stratification frequency, shown in Figure 6(a) was used to examine the degree of stratification in terms of its static stability. The water column was assumed to be in the static condition, and the compressibility was neglected because of the shallow depth. According to Figure 6, between the beginning of southwest monsoon in June and the monsoon transition month in October, the stratification in June was stronger when compared to October, and the stratification also varied in nearshore and offshore areas for each cruise.

A restoring buoyancy force acts on a water parcel when it is displaced from its initial location, leading to an oscillation. When the Brunt-Vaisala frequency is greater than zero, $\mathrm{N}^{2}>0$, it implies oscillations with a frequency of $\mathrm{N}$. In this state, the stratification is stable and the water parcels do not return to their original density. The water column is also stable if the density increases with the depth. By comparing the results of $\mathrm{N}^{2}$, density, temperature and salinity, the stratification frequency was found at a maximum within the pycnocline, thermocline and halocline layer. In the nearshore area (103.5E - 103.8E) in June, strong stratification at an approximately 15 - $35 \mathrm{~m}$ depth was observed (Figure 6(a)). The temperature and salinity profiles also showed that in June, the thermocline and halocline occurred at approximately the same depth as where the higher positive values of $\mathrm{N}^{2}$ were found (Figure 6(b) \& Figure 6(c)).

October data showed a Brunt-Vaisala frequency of almost 0 . Instabilities in the ocean, $\mathrm{N}^{2}<0$, where the parcels overturned to their original density, induced the mixing of the ocean. Weaker $\mathrm{N}^{2}$ values $\left(\mathrm{N}^{2} \approx 0\right)$ indicated that the stratification was reduced but not destroyed, which means that a very little stratification was present at the nearshore area of east coast Peninsular Malaysia during this monsoon transition period. Stratification was weakened near the vicinity of offshore stations; hence, vertical mixing was enhanced until a depth of $\sim 50 \mathrm{~m}$. Greater stratification was observed after this depth.

Coastal surface wind data obtained from the nearest location of the cruise showed winds during June cruise were weaker and ranged from $0-3.3 \mathrm{~m} / \mathrm{s}$ (Table 5). Strong westward currents flow from the bottom offshore to the subsurface of nearshore area that bring together denser water mass in June caused the pycnocline layer to be found in shallower water column. The temperature values in June were also higher than in October. Weaker 

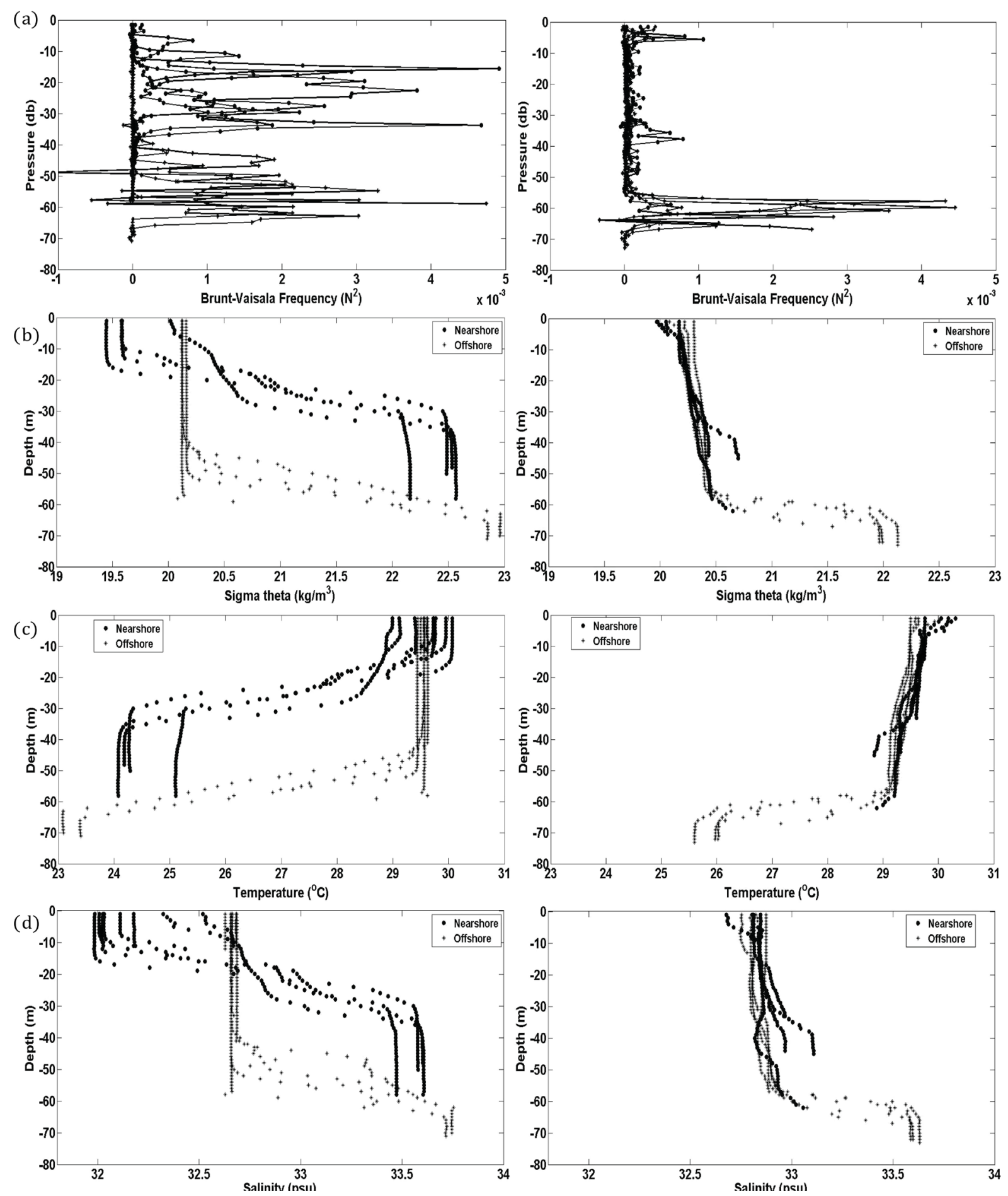

Figure 6. Vertical profiles of nearshore and offshore stations for (a) brunt vaisala frequency ( $\left.\mathrm{N}^{2}\right)$, (b) density, $\sigma_{T}\left(\mathrm{~kg} / \mathrm{m}^{3}\right)$, $(\mathrm{c})$ temperature $\left({ }^{\circ} \mathrm{C}\right)$ and (d) salinity (psu); the comparison between June (left) and October (right).

wind and greater sea surface heating [16] in the absent of ENSO event in 2012 stabilized stratification. The vertical distribution of water masses in both months was varied according to this feature. WM1 was more dominant in the October compared to June while WM2 was most dominant in June compared to in October. This is happened because of the stable stratification in June and mixing in October. WM2, the stratified water mass was found at the thermocline layer. The stable thermocline and halocline in June prevents WM2 to mix with WM1 
and WM3 to mix with WM2. This had caused the WM3 to sink below WM2. This strong stratification explained the existence of WM3 in June and absent in October. During October cruise, wind are stronger but varies in direction, ranged from $0.5-4.1 \mathrm{~m} / \mathrm{s}$ (Table 2). The water column experienced mixing because of this northeast monsoon wind. The stratified water mass, WM2 was found at the most bottom part of the ocean and almost vanish due to stronger wind that enhanced mixing at the upper layer. WM1 was dominating almost the whole water column while WM3 was absent in October.

\section{Conclusions}

The CTD data obtained from two oceanographic cruises taken in June and October showed that the water masses during both months shared the same properties of a southwest monsoon. Both cruises shared two similar water masses; warmer surface water, WM1, $\left(29^{\circ} \mathrm{C}-31^{\circ} \mathrm{C}\right.$; $\left.32-33.5 \mathrm{psu} ; \sigma_{\mathrm{T}}=19.5-20.7 \mathrm{~kg} / \mathrm{m}^{3}\right)$, and stratified water, WM2, $\left(25^{\circ} \mathrm{C}-29^{\circ} \mathrm{C}\right.$; $\left.32.8-33.8 \mathrm{psu} ; \sigma_{\mathrm{T}}=22.3-23 \mathrm{~kg} / \mathrm{m}^{3}\right)$; and one heavy water mass that was only observed in the June cruise, WM3 $\left(23^{\circ} \mathrm{C}-25^{\circ} \mathrm{C} ; 33.5-34 \mathrm{psu} ; \sigma_{\mathrm{T}}=22.3-23.3 \mathrm{~kg} / \mathrm{m}^{3}\right)$. From the northern to the southern part of east coast peninsular Malaysia, both WM1 and WM2 distribution is almost similar. These water masses also can be found in Vietnamese water and Taiwan Straits, located at the northwestern of the study area. This suggested that these water masses were transported from the Pacific water, as discussed by [8] and enter the study area with some modification. Water masses define in this study cannot specifically characterize according to previous definition since the bathymetry and geographical condition and the monsoon intensity during study period were different.

Although both cruises shared similar southwest monsoon T-S curves, the stratification was clearly varied between both months. Stronger nearshore stratification was found in June compared to October, in which no discernible stratified layer was found. At the offshore area, the stratification occurred in the deeper layer of both cruises. A shallower thermocline, halocline and pycnocline were observed in June (40 - $50 \mathrm{~m}$ ), which were deeper in October (55 - $60 \mathrm{~m}$ ). Stable stratification allows the denser water mass to remain below the less dense water at the whole water column. In October, where the upcoming northeast monsoon wind blew caused the mixing to be occurred. The stronger wind and decreasing temperature during this period enhanced the vertical mixing and produced a deeper, well mixed layer.

\section{Acknowledgements}

The authors wish to thank the staff from Universiti Malaysia Terengganu (UMT), Universiti Kebangsaan Malaysia (UKM), Malaysia Fisheries Institute, and The First Institute of Oceanography (FIO), China who involved in these scientific research cruises for their contribution and support. This study was supported by the Science Fund grant, from Ministry of Science, Technology and Innovation (MOSTI) (04-01-02-SF0747), Long Term Research Grant (LRGS/TD/2011/UKM/PG/01) and Higher Institution Centre of Excellence Fund (HICOE). It is also important to mention that this study was a collaborative effort between UMT (Malaysia), UKM (Malaysia) and FIO (China) under the regional development project of Ocean Forecast System (OFS) which is part of Southeast Asia Global Ocean Observation System (SeaGOOS) program under the auspices of UNESCO/IOC WESTPAC.

\section{References}

[1] Wyrtki, K. (1961) Physical Oceanography of the Southeast Asian Waters. Scripps Institution of Oceanography, The University of California, La Jolla.

[2] Hu, J., Kawamura, H., Hong, H. and Qi, Y. (2000) A Review on the Currents in the South China Sea: Seasonal Circulation, South China Sea Warm Current and Kuroshio Intrusion. Journal of Oceanography, 56, 607-624. http://dx.doi.org/10.1023/A:1011117531252

[3] Huang, C.Y., Wu, S.F., Zhao, M., Chen, M.T., Wang, C.H., Tu, X. and Yuan, P.B. (1997) Surface Ocean and Monsoon Climate Variability in the South China Sea since the Last Glaciation. Marine Micropaleontology, 32, 71-94. http://dx.doi.org/10.1016/S0377-8398(97)00014-5

[4] Taira, K., Nasir, M., Kitagawa, S. and Yanagi, T. (1996) Observation of Temperature and Velocity in the Coastal Water off Kuala Terengganu, Malaysia. Journal of Oceanography, 52, 251-257. http://dx.doi.org/10.1007/BF02235673

[5] Hui, Z., Dongliang, Y., Ruixiang, L. and Lei. H. (2010) The Western South China Sea Currents from Measurements by Argo Profiling Floats during October to December 2007. Chinese Journal of Oceanology and Limnology, 28, 398-406. 
http://dx.doi.org/10.1007/s00343-010-9052-z

[6] Chu, P.C. and Guihua, W. (2003) Seasonal Variability of Thermohaline Front in the Central South China Sea. Journal of Oceanography, 59, 65-78. http://dx.doi.org/10.1023/A:1022868407012

[7] Akhir, M.F.M. (2012) Surface Circulation and Temperature Distribution of Southern South China Sea from Global Ocean Model (OCCAM). Sains Malaysiana, 41, 701-714.

[8] Dippner, J.W. and Loick-Wilde, N. (2011) A Redefinition of Water Masses in the Vietnamese Upwelling Area. Journal of Marine Systems, 84, 42-47. http://dx.doi.org/10.1016/j.jmarsys.2010.08.004

[9] Chua, T.E. (1984) Physical Environments of the East Coast of Peninsular Malaysia. University Science Malaysia Press, Penang.

[10] Morgan, J.R. and Valencia, M.J. (1983) The Natural Environment Setting. University of California Press, Berkeley.

[11] Saadon, M.N. and Camerlengo, A. (1996) Interannual and Seasonal Variability of the Mixed Layer Depth of the South China Sea. In: Proceedings of the National Conference on Climate Change, Universiti Putra Malaysia, Serdang, 141151.

[12] Rojana-Anawat, P., Pradit, S., Sukramongkol, N. and Siriaksophon, S. (2000) Temperature, Salinity, Dissolved Oxygen and Water Masses of Vietnamese Waters. In: Proceeding of the Fourth Technical Seminar on Marine Fishery Resources Survey in the South China Sea, Area IV: Vietnamese Waters, 291-307.

[13] Hu, J., Hong, H., Li, Y., Jiang, Y., Chen, Z., Zia, J., Wan, Z., Sun, Z. and Liang, H. (2011) Variable Temperature, Salinity and Water Mass Structures in the Southwestern Taiwan Strait in Summer. Continental Shelf Research, 31, 512523. http://dx.doi.org/10.1016/j.csr.2011.02.003

[14] Marghany, M.M., Saadon, M.N., Hussain, M.L. and Mohamed, M.I. (1996) Seasonal Thermohaline Variation in Coastal Waters off Kuala Terengganu, Malaysia. In: Proceedings of the National Conference on Climate Change, Universiti Putra Malaysia, Serdang, 152-167.

[15] Akhir, M.F., Sinha, P.C. and Hussain, M.L. (2011) Seasonal Variation of South China Sea Physical Characteristics off the East Coast of Peninsular Malaysia form 2002-2010 Datasets. International Journal of Environmental Sciences, 2, 569-575.

[16] Yanagi, T., Sachoemar, S.I., Takao, T. and Fujiwara, S. (2001) Seasonal Variation of Stratification in the Gulf of Thailand. Journal of Oceanography, 57, 461-470. http://dx.doi.org/10.1023/A:1021237721368

[17] Large, W.G. and Pond, S. (1981) Open Ocean Momentum Flux Measurements in Moderate to Strong Winds. Journal of Physical Oceanography, 11, 324-336. http://dx.doi.org/10.1175/1520-0485(1981)011<0324:OOMFMI>2.0.CO;2

[18] Rousseeuw, P.J. (1987) Silhouettes: A Graphical Aid to the Interpretation and Validation of Cluster Analysis. Journal of Computational and Applied Mathematics, 20, 53-65. http://dx.doi.org/10.1016/0377-0427(87)90125-7

[19] Chen, G., Jaradat, S.A., Banerjee, N., Tanaka, T.S., Ko, M.S.H. and Zhang, M.Q. (2002) Evaluation and Comparison of Clustering Algorithms in Analyzing ES Cell Gene Expression Data. Statistica Sinica, 12, 241-262.

[20] Molleri, G.S.F., Kampel, M. and Novo, E.M.L. de M. (2010) Spectral Classification of Water Masses under the Influence of the Amazon River Plume. Acta Oceanologica Sinica, 29, 1-8. http://dx.doi.org/10.1007/s13131-010-0031-1

[21] McDougall, T.J., Jackett, D.R., Barker, P.M., Roberts-Thomson, C., Feistel, R. and Hallberg, R.W. (2010) A Computationally Efficient 25-Term Expression for the Density of Seawater in Terms of Conservative Temperature and Related Properties of Seawater. To Be Submitted to Ocean Science Discussions.

[22] Chen, C.T.A. and Wang, S.L. (2006) A Salinity Front in the Southern East China Sea Separating the Chinese Coastal and Taiwan Strait Waters from Kuroshio Waters. Continental Shelf Research, 26, 1636-1653. http://dx.doi.org/10.1016/j.csr.2006.05.003

[23] Chen, C.T.A. and Hsing, L.Y. (2005) Degree of Nutrient Consumption as an Aging Index of Vertically Mixed Water in the Northern Taiwan Strait. Acta Oceanologica Sinica, 24, 115-124. 